\title{
Challenges and Opportunities for Implementing Recognition of Prior Learning at the University of Namibia
}

\author{
Lydia L. Shaketange \\ University of Namibia, Windhoek,', Namibia \\ Email:1shaketange@unam.na
}

How to cite this paper: Shaketange, L. L. (2018). Challenges and Opportunities for Implementing Recognition of Prior Learning at the University of Namibia. Creative Education, 9, 2070-2087. https://doi.org/10.4236/ce.2018.913150

Received: July 19, 2018

Accepted: October 23, 2018

Published: October 26, 2018

Copyright $\odot 2018$ by author and Scientific Research Publishing Inc. This work is licensed under the Creative Commons Attribution International License (CC BY 4.0).

http://creativecommons.org/licenses/by/4.0/ (c) (i) Open Access

\begin{abstract}
The University of Namibia (UNAM) has developed and approved a policy on the recognition of prior learning (RPL), but the implementation thereof is dormant. The purpose of this paper is to present potential challenges and opportunities that can influence the implementation of RPL at UNAM. The paper used a qualitative approach and the phenomenological design to solicit participants' views, perceptions and experiences concerning RPL at UNAM. Semi-structured interview schedules were employed to collect data from 12 staff members of UNAM who were purposively chosen based on their positions that are key to providing information to answer the research questions. The findings reveal opportunities such as the availability of political will to implement RPL at the institution, the availability of expertise, capability in terms of technology and infrastructure, the availability of RPL policy, quality assurance and the assessment policy of the institution. Challenges identified are lack of ontological knowledge of what counts as RPL, how it is assessed and its validity and integrity. The data reveal high demands regarding training on issues of assessment and raising awareness of RPL at the institution. The paper recommends that the Ministry of Education, the Namibia Qualifications Authority and the National Council of Higher Learning spearhead a campaign to raise awareness and sensitize the nation as to the significance of RPL. It also recommends that RPL be perceived as an assessment strategy of which the outcomes bring about admission, but is not by itself an admission issue.
\end{abstract}

\section{Keywords}

Recognition of Prior Learning, Access, Assessment, Experiential Learning, Ontology, Alignment, Learning Outcomes, Lifelong Learning 


\section{Introduction}

The concept of recognition of prior learning (RPL) is framed within the discourse on lifelong learning, access and social justice. It is a process by which uncertified formal learning, uncertified organised non-formal learning, and uncertified and unplanned informal learning are given academic recognition (Garnett \& Cavaye, 2015). The learning is referred to as prior because it is a form of learning attained before a candidate is assessed in order to gain access to a course of study. The issue of RPL is significant; Berglund and Andersson (2012) acknowledge that knowledge and skills developed through work experience usually remain undocumented and unevaluated through a structured process. If such knowledge and skills were to be formally evaluated, the outcomes could result in upward progression in terms of employment or pursuing of further educational qualifications. It is therefore necessary that discussions of the recognition of learning achievements attained outside formal contexts become part of educational debates.

Access to education is a constitutional right in Namibia, guaranteed by the Namibian Constitution. Being a member of the international community, Namibia is adhering to international frameworks, which calls for nations of the world to ensure equal access to all levels of education and to quality technical, vocational and tertiary education (Tabatadze \& Gorgadze, 2017). Equally, the Namibian National Qualifications Authority (NQA) Act, No. 299 of 1996 stipulates that it recognises all learning, irrespective of the setting where such learning occurred, provided such learning can be verified. Experiential learning is demonstrative in nature and can be justified if appropriate mechanisms are devised. The issue of RPL is not so much about the ability to justify the learning acquired, but the willingness to provide opportunities to assess and justify such learning.

Skinner, Blackley and Green (2010) point out that universities have the capability to not only generate knowledge, but also to develop documentation to support the assessment and verification of knowledge. The RPL is one of the processes that could support these assessments and verifications of learning acquired outside classrooms. Skinner et al. maintain that most institutions that have implemented RPL still experience barriers to implementing the assessment and accreditation of experiential learning. Barriers identified are associated with resistance to the RPL concept due to ontological limitations. Cantwell and Scevak (2004) stress the ontological limitations with regard to what counts as knowledge and who defines the validity of that knowledge. These authors are of the view that such limitation creates fear of lowering entry requirements to institutions, thus causing resistance to the implementation of the RPL concept in higher education. Osman (2003) indicates that in most institutions of higher education, assessment of RPL is often aligned to and resembles methods of assessment used in formal higher education.

Wihak (2006) reports doubts relating to whether prior learning has the calibre 
of formal education and whether contextualised knowledge can match subject knowledge. Skinner et al. (2010) report prejudices against competence-based knowledge in that it is viewed as vocational or corporate rather than as academic skills. Smith (2011) also reports on academics' attitudes towards RPL as that of "if knowledge is not invented here, then it is not credible". Moreover, the literature highlights financial implications as another challenge in the implementation of RPL in higher education, as RPL comes with extra load of labour-intensive performance in relation to assessment (Smith, 2011).

The few examples around the world that could be cited are from publications by Garnett and Cavaye (2015) at the Middlesex University in the United Kingdom, and Gonzales and Tabarak (2016) in France and in South Africa. The Middlesex University has developed a policy and approved regulations for accrediting learning from experience. They have established quality assurance principles and procedures to enable the accreditation to be conducted within the mainstream quality assurance framework of the University. They award specific credit, which implies a direct match between the submitted learning evidence and the learning outcomes of specific modules. General credit where no specific match is made, is also employed despite no details having been shared on how this is conducted. The Gonzales and Tabarak (2016) study holds that in France RPL implementation in higher education is made on the basis of candidates' professional knowledge. The assessment involves candidates' ability to prove the achievements of learning at the level of intellectual development corresponding to the level required at the institution (Gonzales \& Tabarak, 2016). They also explain that in South Africa RPL is philosophically framed in the discourse of access, equity and redress. Most admissions made on the basis of RPL are into professional programmes such as selected health sciences, engineering and computer science. Gonzales and Tabarak claim that there is evidence that RPL in South Africa is being offered across the higher education spectrum except at doctoral level. Also in South Africa, students are admitted to higher education through RPL by completing a portfolio. Gonzales and Tabarak argue that credibility and integrity in the assessment of RPL in South Africa are inherent in the use of well-developed and crafted principles, standards, models and procedures.

The University of Namibia (UNAM) established an alternative admission route for entry into its programmes by adults who lack the traditional entry requirements. Adults who have completed Grade 10 (ten years of schooling) and have gained five years' work experience relevant to the field in which they want to study, are considered under the Mature Age Entry (MAE) system. The MAE is one form of RPL, as it considers candidates that would traditionally not be accommodated. However, it recognises certificated learning and does not consider the assessment of experiential and work-based learning. Shaketange (2014) holds the view that candidates who go through the MAE system only have knowledge that resembles subject knowledge, and are not adequately prepared to reflect and demonstrate what they have learned from their professional practices; 
in most cases these students are often less qualified for the specific field of study they apply for. Moreover, credit transfer is also awarded at UNAM, but this service relates to awarding credits to similar subjects or modules passed at other institutions. It does not award credit to the learning previously acquired. In 2017, UNAM developed an RPL policy to guide the implementation of RPL in the institution, but the policy is dormant. Given the constant resistance to the implementation of RPL at institutions of higher learning internationally, this study aims to explore ways that UNAM intends to avoid similar ontological challenges as identified in the literature. The study explores opportunities that could lead to a successful implementation of RPL at UNAM. The presentation of topics in this article follows the sequence below:

- Presentation of the problem statement

- Discussion of the theoretical framework, description of the research design, strategy and methodology

- Presentation of data

- Discussion of the findings

- Conclusion and recommendations

\section{Statement of the Problem}

Whereas UNAM wished to honour its national obligation towards inclusive education, the literature (Cantwell \& Scevak, 2004; Osman, 2003; Wihak, 2006; Skinner et al., 2010) stresses ontological limitations as the most critical challenges capable of crippling implementation efforts of RPL in higher education. UNAM needs to employ strategies that would curb ontological limitations if successful implementation of RPL is to be realised at the institution. This article investigates possible challenges to opportunities available to respond to identified ontological limitations for a sustainable implementation of RPL at UNAM.

This article will address the following research questions:

- What opportunities are available for implementing RPL at UNAM?

- What are potential challenges that could hinder the implementation of RPL at UNAM?

- What suggestions can be made to deal with ontological limitations in the implementation of RPL at UNAM?

- What is the role of existing quality assurance structures in the implementation of RPL at UNAM?

- What would be the ideal location for the RPL office that may aid the implementation of RPL at UNAM?

\section{Theoretical Framework}

This study is grounded in critical theory, which came into existence in 1894 and evolved due to the transformation of society brought about by revolutionaries at the Institute for Social Research at Frankfurt University, to redress political injustices in Germany (Nel, 1998). Critical theory therefore emerged as a tool for 
expressing the sentiments felt, and was an instrument for changing the future. Equally, critical theory in this article questions the ideology and ontological basis on which subject knowledge is anchored, to become the prestigious sole representation of knowledge. With Skinner et al. (2010) calling for a bridge between academic and vocational skills, questions have started to emerge expressing sentiments about the sole representation of subject knowledge. Garnett (2016) clearly expresses that universities no longer hold sole supremacy of knowledge production; they are facing stiff contestation from the workplace, which demands recognition as an equal knowledge production site. This contestation is perceived as an instrument for changing the traditional ideological view held about supremacy of subject knowledge. The current sentiments are that knowledge is vibrant, and is gathered from diverse sites. Universities should acknowledge the multiplicity of knowledge production sites and admit the need for varied assessment tools of such knowledge.

\section{Methodology}

A phenomenological design of the qualitative approach was used in the study on which this article is based. Phenomenological design assumes that access to reality and knowledge is only achieved through social interaction. Within this view, the researcher came to understand participants' feelings and convictions and was able to makes sense of the expressed opportunities and challenges for implementing RPL at UNAM.

\subsection{Population and Sampling}

The purposive sampling strategy was used to select respondents from the population of 1200 UNAM employees on the main campus. Purposive strategy was significant to select informants who by virtue of their duties were perceived to possess rich information to answer the research questions. Twelve (12) staff members were purposively sampled from the office of the Pro-Vice Chancellors, the office of the Registrar, Quality Assurance Unit, and Deans of Faculties. This sample population occupies offices that are strategic to the implementation of RPL at UNAM. The Pro-vice Chancellors' offices have the management will required for the successful implementation of RPL. Quality Assurance is needed to monitor and assess quality in every step of RPL implementation. The Registrar office deals with admission of students and Deans of Faculties are critical to agree with the implementation strategies since the faculties will implement RPL in practice. Therefore, the sample comprised respondents who would influence the implementation of RPL at the institution positively or negatively. Patton (1990) clarifies that qualitative inquiries are more concerned about quality of information collected, than the quantity of informants.

\subsection{Research Instruments and Data Collection Procedures}

Asemi-structured interview schedule was employed to solicit the experience, 
knowledge and opinions about favourable opportunities to implement RPL and potential challenges that may hinder its implementation at UNAM. All participants were asked to answer research questions one to three, while inputs on quality assurance issues and the location of the RPL office were solicited from CEQUAM and offices of the pro-vice chancellors and the registrar respectively. The semi-structured interview was significant as it allowed new ideas to emerge. For comprehensive data-capturing and triangulation purposes, participants granted permission for the use of a tape recorder during interviews.

\subsection{Data Analysis}

Since interview questions were recorded and data were transcribed into text, content analysis became relevant to analyse the data. Data analysis started with the transcription of interviews and the organisation thereof according to questions. Related answers were marked, grouped, labelled, compared and inductively generated into categories. For the purpose of reduction, the process of comparisons between properties in different categories was followed to form broad themes (Creswell, 2009). Data from categories were linked and aggregated across broad themes until themes of a manageable size emerged.

\subsection{Ethical Considerations}

Permission was sought from the UNAM Research and Publications Unit to interview the relevant UNAM staff members. Written informed consent from individual participants was prearranged. Participants were clearly informed of their right to withdraw from the research at any time, and were assured that their identities and privacy would be protected through anonymity and confidentiality of the collected data.

\section{Presentation and Interpretation of Data}

\subsection{Opportunities Available for Implementing RPL at UNAM}

The opportunities available for implementing RPL at the institution are presented in Table 1.

Table 1 shows that some of the respondents felt that UNAM was ready, and that RPL was long overdue. Others were ambivalent in that there are issues that UNAM must address to become ready to implement RPL. These respondents explained that although the majority of UNAM staff agree that RPL should be implemented, there was a lack of RPL formal structure, resources and capacity-building opportunities. Most respondents maintained that RPL could be implemented provided that issues such as the integration of programme delivery and admission requirements pertaining to the respective department programmes were addressed. If the system for programme development and NQF registration was linked to the RPL and if UNAM puts formal structures in place, trains implementers, and avails resources, then it could be ready. One respondent stressed that the RPL process requires more manpower than that which 
Table 1. Responses as to whether UNAM is ready to implement RPL.

\begin{tabular}{cl}
\hline Respondents & \multicolumn{1}{c}{ Responses } \\
R1 & $\begin{array}{l}\text { UNAM could be ready, provided system for programme development } \\
\text { and [if] NQF registration is linked to RPL process. }\end{array}$ \\
R2 & $\begin{array}{l}\text { We are ready, but before we implement RPL, we need to be sure that } \\
\text { everybody understands what RPL is about. }\end{array}$ \\
R4 & Yes, we are committed to implementing it. \\
R5 & UNAM is committed, not ready until formal commitment is made. \\
R6 & $\begin{array}{l}\text { Yefinitely, Yefinitely-RPL is long overdue. } \\
\text { R7 }\end{array}$ \\
Yes, I think we are ready. \\
Yes and No. \\
Yes, in terms of desire as most people are in agreement \\
with the implementation of RPL. \\
No, in terms of carrying out activities such as the full-fledged \\
implementation, unless if we pilot it first.
\end{tabular}

UNAM currently has on the ground. UNAM needs to raise awareness about RPL, develop and understand the guidelines, and clarify the criteria for assessing experiential learning before the implementation of RPL. The assertions demonstrated above show that the institution in its present state does not seem to be ready to implement RPL.

\subsection{Opportunities Available to Implement RPL at UNAM}

The respondents indicated that UNAM has both international and national imperatives which call for RPL implementation and that Agenda 2030 is an international authoritative tool which the Namibian nation needs to apply to ensure equal access to education. The respondents made references to the Namibian Constitution which stipulates the right to education, and the NQA Act that recognises all learning, irrespective of its setting. Respondents also made reference to the National RPL policy, the UNAM-RPL policy as well as the Vision and Mission of UNAM. As stated by one of the respondents:

"The international and internal imperatives, Agenda 2030, the Namibian Constitution, the NQA Act which calls for the need of RPL, the UNAM policy are all instruments that UNAM is responding to. Also, RPL fits well within the 
vision, mission of UNAM."

The respondents clarified that the RPL provision fits well within the vision and mission of UNAM as both are framed within the government's agenda of economic development and quality of life. Another respondent mentioned the strong political will for RPL at the university:

"The political will. Management at UNAM are in agreement with the implementation of RPL."

One respondent explained that UNAM has the capabilities in terms of resources and technology.

"UNAM has the capability, available technology, skilled people, resources, an approved RPL policy, all these create [an] enabling environment for the implementation of RPL at the institution."

These viewpoints on RPL underscore support for the implementation of and belief in the high probability of RPL succeeding at the institution.

\subsection{The Challenges that Can Hinder the Implementation of RPL at UNAM}

The challenges that might hinder the implementation of the RPL concept at UNAM are presented in Table 2.

Table 2. Challenges that might inhibit the implementation of the RPL concept at UNAM.

\begin{tabular}{|c|c|}
\hline Respondents & Responses \\
\hline $\mathrm{R} 1$ & $\begin{array}{l}\text { Lack of knowledge on assessment of learning and the } \\
\text { validation of the competences possessed. }\end{array}$ \\
\hline $\mathrm{R} 2$ & $\begin{array}{l}\text { Lack of understanding what RPL is about and negative } \\
\text { preconceived ideas about RPL. }\end{array}$ \\
\hline $\mathrm{R} 3$ & Lack of trained manpower to handle the RPL process. \\
\hline $\mathrm{R} 4$ & $\begin{array}{l}\text { Resistance from Faculties, academics that may not be } \\
\text { fully aware of why RPL is important. }\end{array}$ \\
\hline $\mathrm{R} 5$ & Lack of trained people such as assessors, implementers. \\
\hline R6 & Lack of knowledge in assessing portfolios at Department level. \\
\hline R7 & Difficulties to fit RPL into Faculty programmes. \\
\hline $\mathrm{R} 8$ & $\begin{array}{l}\text { Lack of experience in dealing with RPL, availability of resources both } \\
\text { human and financial, candidates not knowing how to compile a portfolio, } \\
\text { and assessing the portfolios. }\end{array}$ \\
\hline R9 & $\begin{array}{l}\text { Overflow of applicants might overwhelm the institution, difficulty in } \\
\text { selecting relevant students, inability to recognise informal knowledge, } \\
\text { inability to identify the required knowledge-what constitutes } \\
\text { the knowledge that deserves recognition? }\end{array}$ \\
\hline R10 & $\begin{array}{l}\text { Integrating the mature students with graduates of Grade } 12 \text {, } \\
\text { comparability of experience against Grade } 12 \text {. How can knowledge } \\
\text { from Shoprite be compared against knowledge from NAMDEB. }\end{array}$ \\
\hline R11 & Lack of awareness. \\
\hline $\mathrm{R} 12$ & Lack of knowledge on how to assess RPL. \\
\hline
\end{tabular}


According to Table 2, all respondents concur with three critical challenges, namely the ontological limitations of RPL, which include the lack of knowledge in assessing experiential learning and the lack of resources at the institution. The ontological limitation refers to knowledge of RPL: What constitutes RPL knowledge, and how is informal learning identified and recognised? What credibility or worth does RPL knowledge have in comparison to subject knowledge? The assessment of RPL knowledge includes: The ability to identify sufficient evidence for assessment; how is the actual assessment done? What constitutes the knowledge that deserves recognition? How is the validation of the competencies done? Who constitutes the assessment team? Respondents felt that lack of answers to these questions has the potential to culminate in negative preconceived ideas about RPL. Respondents therefore call for the training of all those who would be concerned with the implementation of RPL at UNAM.

Another challenge identified was the lack of resources at the institution. Despite indications by some respondents that UNAM does have the resources, the majority of respondents pointed out human and financial resources as challenges that may derail the implementation of RPL. The concern here was that experts in RPL are too few to launch RPL and meet its demands. Apprehension was raised regarding academic support to older students where needed; the team of implementers of RPL needs to be adequate to implement a successful innovation. Financial resources were stated as a concern in view of the few available experts who might need the assistance of additional staff, resulting in extra remuneration.

\subsection{Suggestions to Facilitate the Implementation of RPL at UNAM}

The respondents' suggestions about interventions to aid the implementation of RPL at UNAM are outlined in Table 3.

Table 3 shows that awareness campaigns to educate the UNAM community about RPL and its significance werestrongly suggested. It appears that different role-players need to take responsibility for marketing the RPL concept. For example, the Communication and Marketing Division at UNAM could mobilise and inform the UNAM community about RPL. It was also suggested that RPL is a national issue and would require national intervention. Therefore, the Ministry of Education and the NQA, which is the custodian of this endeavour, together with NCHE should launch a national campaign advocating for the implementation of RPL. It was also suggested that UNAM should be the initiator of this national advocacy campaign. Such a campaign would boost the significance of RPL and avoid any form of stigmatization that may be attached to RPL out of ignorance. Another suggestion pertained to benchmarking the Namibian RPL with similar institutions that have implemented RPL, so as to ascertain what situations and challenges might block the RPL progress. A suggestion to begin RPL services at postgraduate level was also made. This would avoid the inflow of applicants for undergraduate programmes. Ontological questions need to be answered to facilitate understanding and give clear guidance as to how evidence of 
Table 3. Suggestions for implementing RPL at UNAM.

\begin{tabular}{|c|c|}
\hline $\mathrm{R} 1$ & $\begin{array}{l}\text { RPL should be done through and with the requirements of } \\
\text { programme development and NQF registration. }\end{array}$ \\
\hline $\mathrm{R} 2, \mathrm{R} 4$ & $\begin{array}{l}\text { Awareness campaign to unlock people's preconceptions of RPL. } \\
\text { RPL should be piloted before full implementation. }\end{array}$ \\
\hline R3 & $\begin{array}{l}\text { To have clear instructions of how to assess RPL and a } \\
\text { template of portfolio and how assessment is done. }\end{array}$ \\
\hline R5 & Establishment of the RPL Unit be given priority. \\
\hline R6 & $\begin{array}{l}\text { Train implementers. UNAM to raise awareness about RPL to ensure ownership. } \\
\text { We have the Directorate of Communication and marketing. }\end{array}$ \\
\hline R7 & Special care given to adult learners. \\
\hline R8 & Start RPL with postgraduates rather than undergraduates. \\
\hline R9, R12 & Benchmarking with related Universities. \\
\hline R10 & Allow candidates to write a test to determine competences. \\
\hline R11 & $\begin{array}{l}\text { National awareness campaigns initiated and spearheaded by UNAM and supported } \\
\text { by the Ministry of Education, NQA, and NCHE. }\end{array}$ \\
\hline
\end{tabular}

learning is identified, assessed and validated. There is a need for rubrics and a clear rationale to facilitate smooth implementation. It was suggested that the assessment of RPL be made through and with programme development and NQF registration, and that a simple entrance test be introduced to measure the entry capability of candidates.

\subsection{The Role of Existing Quality Assurance Structures in the Implementation of RPL at UNAM}

The officials from CEQUAM were solicited to state CEQUAM's role in the implementation of RPL at UNAM. Below are their responses:

\footnotetext{
R1 UNAM has a quality assurance policy and a policy on curriculum development, these policies are there to guide and assure quality.

CEQUAM will ensure that the assessment that will be done through RPL is in line

R2 with the principles of assessment. There must be RPL guidelines that will guide the practice of assessment. accommodate[s] all academic programme[s] and RPL will be included.
}

CEQUAM officials stipulated their role in the implementation of RPL as ensuring quality in the assessment process of RPL, and to guarantee that RPL procedures follow the principles of the UNAM assessment policy.

\subsection{Location of the RPL Office to Aid the Implementation of RPL at UNAM}

Respondents from the offices of the Pro-vice Chancellors and office of the Registrar had different views as to where the office of the RPL should be located to 
aid the implementation of RPL at UNAM. Some respondents felt it should resort under the office of the Registrar because RPL is an admission matter. Others respondents indicated that it should fall under the office of the Pro-vice Chancellors-Academic Affairs because this would give RPL a respectful profile. Another opinion was that it should be independent, given that RPL is an assessment issue and not an admission matter. It was emphasised that only the outcome of the RPL assessment leads to admission, therefore, it should be independently administered in conjunction with the various faculties. Some respondents thought it should be under the Quality Assurance Unit since it deals with NQA frameworks and standards, which are quality matters.

\section{Discussion of the Findings}

The discussion of findings will reflect on international and national imperatives, the need for political will at UNAM and the capability and constraints of UNAM to implement RPL. This section will also reflect on the potential challenges that could hinder the implementation of RPL at UNAM and attempt to answer the ontological questions raised during data collection.

\subsection{International and National Imperatives}

The implementation of RPL at UNAM is said to be anchored in both international and national imperatives. Namibia, being a member of these international treaties, is responding through its educational institutions. UNAM's intention to implement RPL is based on fulfilling its national duty to bring about social justice. Equally, the UNAM Act, Act 18 of 1992, section 18directs that it may not confer a degree upon any person unless he or she has attended or attained the standards of proficiency in an examination or tests as determined by Senate. The Act paves the way for the provisions of RPL assessment. Equally, UNAM's vision and mission promote the development of individuals capable of driving public and private institutions towards a knowledge-based economy.

\subsection{The Political Will at UNAM}

The matter of political will at UNAM was mentioned as an opportunity which favours the implementation of RPL. The policy was developed, together with the implementation guide. The political will in the context of RPL was justified by the institution's highest decision-making body, the Senate, who in 2017 adopted a resolution to approve the RPL policy. However, the implementation thereof is latent. The dormancy of the implementation of the approved policy contradicts the will unanimously expressed during data collection. Osman (2003) and Gonzales and Tabarak (2016) emphasise that policies and the managerial will of RPL are best understood in terms of practices, rather than in terms of idealistic statements of intentions. The proclaimed will by respondents at UNAM to implement RPL appears to be only idealistic statements of intention, with no commitment to put the implementation plan into practice. If implementation of RPL 
at UNAM is to be sustained, it certainly requires much stronger commitment than the idealistic intention exhibited by respondents during data collection.

\subsection{RPL Capability and Constraints at UNAM}

The data reveal that despite UNAM's possession of technology, expertise and resources that were seen to provide a conducive environment for the implementation of RPL, the implementation of RPL at the institution is still being ignored. There appears to be a lack of felt need at UNAM to devote sufficient effort to RPL. Petersen and Osman (2013) call for higher education to realise that conventional classroom learning emphasises learning of subject matter and literature, which might be one-sided knowledge, and inadequate for practice. Petersen and Osman stress that just as university students need service knowledge through internships and practical attachments to balance their learning, candidates from workplace backgrounds would equally need academic learning to balance their service learning. Peterson and Osman caution that one-sided learning, irrespective of context, remains inadequate, insufficient, and often external to the local context. Therefore, UNAM should use the capability revealed in the data to embrace mobility between workplace and education as a way to contribute to the country's competent and productive human resources, capable of shifting Namibia from a resource-based to a knowledge-based economy. Therefore, the policy should be functional to convey the purpose of its development.

\section{Potential Challenges that Can Hinder the Implementation of RPL at UNAM}

Challenges to implementing RPL were divided into two main categories: lack of resources and ontological limitations.

\subsection{Lack of Resources at the Institution}

There were conflicting responses to the question of resources' availability to aid the implementation of RPL at UNAM. Some respondents maintained that resources are available, while others stated the lack thereof. The conflicting views insinuate the extent of devotion to the implementation of RPL at UNAM. There seems to be no felt need for the RPL implementation at the institution. If there is no agreement as to whether or not resources are available to accommodate RPL, it conveys a serious lack of interest on the institution's part in the RPL process. Most institutions that are not committed to the course often tend to base their arguments on the lack of resources in order to delay the implementation process.

\subsection{Ontological Limitations}

The question of ontological understanding is divided into subgroups: 1) what constitutes RPL knowledge, its credibility and integrity in the academic milieu, and 2) how is it assessed, the identification of sufficient evidence, the ability to 
know which knowledge deserves recognition, validation of evidence and who constitute the assessment team.

1) What counts as RPL Knowledge?

Academics in many institutions worldwide have always questioned what constitutes RPL knowledge, its integrity, legitimacy and validity to penetrate the academy. RPL is grounded on the belief that there are other ways of creating knowledge, and there are various sites at which academically credible knowledge can be created. Kolb's learning circle, John Dewey's vision of egalitarian education and his call for a relationship of experience and learning have not only authenticated this argument, they have also given a theoretical legitimacy to experiential learning. What counts as knowledge is the level of learning evidence submitted by the candidates, and the extent to which such learning fits the entry requirements of a specific course. It is clear that the question of RPL in higher education has not doubted the ability of other sites to create knowledge, as higher education encourages internship and attachment programmes in workplaces. The issue in higher education appears to have been a discussion of power, and the traditional role of higher education which perceives itself as "the gatekeeper of knowledge" (Conrad, 2010).

One critical condition of accepting and authenticating work-based knowledge in higher education has been the demand to align such knowledge with subject knowledge. It appears that aligning work-based learning against subject knowledge on its own, creates the authenticity of knowledge gained in the work-place. This becomes difficult to understand, since what counts as knowledge in RPL is not necessarily the extent to which the evidence of learning resembles the subject taught in the programme. It is not possible for a candidate to have known the subjects in the programme's entry level which the candidate is seeking. Knowledge is measured by the level of complexity acquired by the candidate and the ability to exhibit that knowledge. Academics are usually the assessors of subject knowledge against the complexities of the NQF levels that are pitched at certain levels; it should apply the same principles with the assessment of RPL. In the RPL tradition, the supremacy role of academics is limited. Academics have little influence on the evidence of learning submitted. The candidate compiles the portfolio and submits the supposed learning for marking. This procedure differs from the way in which it is done in traditional higher education, during which students are taught and required to reflect on the content they have been taught. Conrad (2010) acknowledges that academics have always held on to the idea of knowledge ownership and the sole right to disseminate and defend that knowledge. If the traditional procedures are interrupted, academics might hardly accept changes. The issue of credibility and legitimacy of RPL in higher education is really about power. If the content is not created in the institution, it is perceived less credible and should be restricted. Peterson and Osman (2013) advise that a university is not only an environment which defines and constructs knowledge, but one which examines and engages with knowledge created in other sites of practice. The same sentiments are shared by Garnett and Cavaye 
(2015) who also caution that the discussion of higher education should focus on how foreign knowledge ought to be assessed, rather than arguing against its credibility and validity which research can identify. Missions of institutions of learning, including UNAM, are devoted to research; ontological issues should therefore not be allowed to constrain the implementation of RPL at the institution whose mission is invested in research. The critical theory used in this study advance the sentiments felt by the community of practice, concerning the marginalisation of knowledge created outside the formal settings of learning. Critical theory questions the basis on which the supremacy of subject knowledge over experiential knowledge is anchored. Ontological understanding is invested in the individual's perceptions of the form of knowledge created outside the formal settings of education.

\subsection{Assessment of Experiential Learning}

Lack of knowledge in assessing experiential learning dominated the responses from interviewees. How experiential learning is assessed, the ability to identify the kinds of knowledge assessed, its scope and complexity were some of the doubts in the minds of most respondents. Interviewees expressed the need for clear instructions and a possible template of a portfolio which spells out explicitly how the assessment is to be conducted. These demands from respondents portray fear of the unknown and reveal that RPL assessment is foreign to the institution and to the lecturers expected to conduct it. Skinner et al. (2010) and Gonzales and Tabarak (2016) warn against this fear, that despite institutional policies, most institutions are still faced with fear and a lack of knowledge about RPL. Correspondingly, interviewees in this study demonstrated a similar fear regarding how experiential learning is assessed. Given this fear, the following question comes to mind in an endeavour to understand the assessment of experiential learning at UNAM:

- How does UNAM plan to assessexperiential learning: how is the assessment done, identification of sufficiency of evidence, which knowledge deserves recognition, validation of evidence and who constitute the assessment team?

In the introduction section of the UNAM Assessment Policy (2013) it is stipulated that UNAM does not constrain the development of alternative or additional forms of effective assessment, and that the policy would consider a wide range of relevant performances information, be it formal, informal, standardised or non-standardised assessment (UNAM, 2013: p. 5). If UNAM does not constrain the development of alternative forms of assessment, then the development of assessment tools for RPL would be embraced. Similarly, UNAM's assessment policy further stipulates that it perceives students as individual beings, with broad spectrums of abilities, skills and knowledge. The understanding of this statement implies that UNAM recognises the individuality of candidates to the extent that the assessment of their proficiencies would follow this noble perception. Therefore, an assessment that examines individuals' claim of knowledge is in agreement with the assessment policy of the institution. 
RPL knowledge is different from subject knowledge. RPL knowledge is experiential; it is not encoded in media, books and articles in the same way as subject knowledge. It is reflective; it resides within the individual's skills or expertise. It involves action and is context specific. Since this knowledge is embedded within individual subjective thinking and is not coded in books, it appears to present stiffer challenges to articulate and eventually to assess. However, assessment of RPL is possible with the use of the alignment of evidence against the NQF levels descriptors.

The use of the National Qualifications Framework (NQF) level descriptors is advocated in this paper as the assessment criteria, which are supposedly the measure of national and international comparability of achieving proficiencies. University departments have the responsibility to describe learning achievements at particular levels of the NQF that indicate the types of learning expected at specific learning outcomes. In the same way, these departments would describe the assessment criteria framed within the descriptors at the level required to access various programmes in the department. Assessment in RPL implies examination of knowledge as extracted from experience. The author of this article concurs with the explanation by Gonzales and Tabarak (2016) that the credibility and integrity in assessment are inherent in the use of well-developed and crafted principles and standard procedures of RPL.

This article proposes the assessment of RPL to take the following into consideration: Departments at Faculties will devise assessment criteria which conform to the entry requirements of their various programmes. Candidates aspiring to register with specific programmes are asked to present their learning evidence in a portfolio of evidence. The learning evidence is measured against the assessment criteria as set by departments. The use of assessment criteria derived from NQF level descriptors is significant as level descriptors do not precisely measure the content achieved, but they provide an indication of the amount of learning acquired; the scope, in-depth and complexity of what is learnt. Although the level descriptors do not measure the content of what is learnt, because candidates have different contents derived from different contexts, the common denominator is the learning achieved, its scope, and complexity of learning.

The NQF levels are currently used at UNAM as directives that express the relative size of qualifications. They can thus be used as assessment criteria for experiential learning. The community of practice in the area of subject matters is essential in constituting the assessment panel. Since higher education graduates are trained for the world of work, it is significant to partner with employers in assessing the complexity of knowledge required in workplaces. Candidates who are assessed through RPL are better prepared for the academic road ahead, they understand what they know, and they are also aware of what they would need to reach the expected standard of academic readiness.

\subsection{Quality of RPL Assessment}

This paper advocates that NQF level descriptors be employed as the assessment 
criteria to determine the scope and in-depths of learning. The design of the portfolio should meet the outcomes or level of difficulties specified in the NQF level descriptors for a given level. The questions or instructions in the portfolio must prescribe what it is that needs to be assessed and indicate the criteria upon which assessment judgement is made. CEQUAM, being the body that controls quality in the institution, has the responsibility to advise academics on issues related to NQF level descriptors where extra assistance is required.

\subsection{Location of RPL Office}

The data show that respondents had different views as to where the office of the RPL should be located. Smith (2011) advises that when an RPL unit resorts under another establishment it is usually doomed to fail. Smith strongly advises that unless the head of the section under which RPL is placed understands RPL and its functions, such head would allocate other duties to RPL officials, suppressing and eventually killing the work of the RPL unit. An independent office is advocated by literature so as to give RPL autonomy in its functions.

\section{Conclusions and Recommendations to Enhance the Implementation of RPL at UNAM}

The main reason why institutions of higher learning are reluctant to implement RPL appears to be a lack of understanding by academics of what RPL is, and how such knowledge is assessed. The credibility and validity of RPL in comparison to subject knowledge come with more perceptions than the reality of the knowledge presented. However, this study has recognised these perceptions and has advocated for the National Qualifications Framework level descriptors, which are the national classification system used to classify the scope and describe the complexity of learning achievements at every level of learning (NQF, 2006) to strongly spearhead the assessment of RPL at UNAM.

The author of this article extends the current knowledge base by arguing that, irrespective of expressed challenges and opportunities, the assessment of RPL is feasible when an alternative route is employed, one that aligns learning evidence with NQF level descriptors as assessment criteria. This route demands that candidates seeking entry to UNAM through RPL demonstrate the acquired learning to fit a complexity of learning outcomes on the NQF levels. Although the level descriptors do not exactly measure the content of learning evidence, they provide an indication of the required amount of learning to be attained at each level, which compares the weight of learning to any of the ten levels on the NQF. If the learning indicates equivalence to NQF level four, for instance, such a candidate would be admitted to the NQF level five in the field for which the candidate has applied. The fact is that UNAM has the capacity in terms of infrastructure and skills; it has the advantage of competing for a wider academic space in terms of students using appropriate alternative routes. This provision would encourage lifelong learning and inclusivity in education. 
Within the confines of the aforementioned discussions, the author recommends the following:

- Since RPL is a new strategy that openly challenges traditional subject knowledge, it can easily be misunderstood and negatively misconstrued. Therefore, to protect its credibility and validity, the Ministry of Education, the NQA and the NCHE should sensitize the nation about RPL and its significance to society.

- The UNAM Directorate of Marketing and Communication should initiate a national sensitization campaign, and then mobilise the UNAM community to acquire a general understanding of RPL.

- The University should live up to its intended drive to remain a national university by contributing to the government's national agendas in terms of creating a knowledge-based economy. Therefore, UNAM should realise its obligation to implement an RPL framed in social justice, lifelong learning and inclusive education.

- Ontological understanding of what counts as knowledge in RPL and the assessment thereof have the potential to derail the implementation of RPL in higher education. Therefore, the academic community at UNAM must be made aware of what counts as RPL, and its assessment procedures.

- The literature highlights that in universities where RPL has been attached to other divisions, such activity has failed, unless the head of the division understands the duties and functions of RPL. It is therefore recommended that an independently located RPL unit be established, which reports directly to the Pro-Vice Chancellor-Academic Affairs (PVCAA).

- RPL is an assessment strategy of which the outcomes bring about admission. It is not an admission strategy and it is not fitting to be placed directly under the office of the Registrar.

- The implementing process must be clearly spelt out, debated by Faculties and agreed to by stakeholders involved in the assessment of RPL.

- Quality of assessment of the RPL must be assured by CEQUAM as guided by Quality Assurance and UNAM assessment policies. Therefore, a panel of assessors must be created, constituting all people concerned in specific fields of assessment.

- All modules at UNAM and assessment criteria must be aligned to NQF level descriptors.

\section{Conflicts of Interest}

The authors declare no conflicts of interest regarding the publication of this paper.

\section{References}

Berglund, L., \& Andersson, P. (2012). Recognition of Knowledge and Skills at Work: In Whose Interest? Journal of Workplace Learning, 24, 73-84. https://doi.org/10.1108/13665621211201670

Cantwell, R. H., \& Scevak, J. J. (2004). Engaging University Learning: The Experiences of Students Entering University via Recognition of Prior Industrial Experience. Higher 
Education Research and Development, 23, 131-145. https://doi.org/10.1080/0729436042000206627

Conrad, D. (2010). Building Knowledge through Portfolios. Learning in Prior Learning Assessment and Recognition (PLAR). The Quarterly Review of Distance Education, 9, 139-150.

Garnett, J. (2016). Work-Based Learning: A Critical Challenge to the Subject-Discipline Structure and Practice on Higher Education. Journal of Higher Education, Skills and Work-Based learning, 6, 305-314. https://doi.org/10.1108/HESWBL-04-2016-0023

Garnett, J., \& Cavaye, A. (2015). Recognition of Prior Learning: Opportunities and Challenges for Higher Education. Journal of Work-Applied Management, 7, 28-37. https://doi.org/10.1108/JWAM-10-2015-001

Gonzales, R. D., \& Tabarak, U. I. M. (2016). Development of Implementation of RPL Policies and Principles in Selected Countries: Implications and Lessons for Bangladesh. Manila: University of Santo Tomas.

University of Namibia (2013). Recognition of Prior Learning Policy. Windhoek: UNAM.

University of Namibia (1992). University of Namibia Act 18 of 1992. Windhoek: UNAM.

Nel, B. (1998). Critical Theory: Origins, Central Concepts and Education. In P. Higgs (Ed.), Metatheories in Philosophy of Education (pp. 123-137). Johannesburg: Heinemann.

Namibia Qualifications Authority (NQA) (2006). Regulations of Setting up a National Qualifications Framework for Namibia. Windhoek: NQA.

Osman, R. (2003). The Recognition of Prior Learning and Emerging Field of Enquiry in South Africa. Johannesburg: University of the Witwatersrand.

Osman, R., \& Petersen, N. (2013). An Introduction to Service Learning in South Africa. Oxford: Oxford University Press.

Patton, M. Q. (1990). Qualitative Evaluation and Research Methods. Town or City? Thousand Oaks, CA: SAGE.

Shaketange, L. N. (2014). Prior Non-Certificated Learning: A Criterion for the Assessment of Experiential Learning for Access to Namibian Institutions of Higher Learning. Windhoek: Namibia.

Skinner, H., Blackey, H., \& Green, P. J. (2010). Accrediting Informal Learning: Drivers, Challenges and Higher Education Responses. Higher Education Skills \& Work-Based Learning, 1, 52-62. https://doi.org/10.1108/20423891111085393

Smith, E. (2011). The New Kid on the Block Has Come Tostay: Lessons from Twelve Years of Recognition of Prior Learning and Implementation in South Africa. (Paper presented at the SAQA National Conference, Johannesburg.)

Sutherland, L. (2006). Challenges and Opportunities for Implementing Recognition of Prior Learning (RPL) Policy in Higher Education Place? Richards Bay: University of Zululand.

Tabatadze, S., \& Gorgadze, N. (2017). Affirmative Action Policy in Admissions System of Higher Education of Post-Soviet Georgia. Journal of Applied Research in Higher Education, 9, 363-377. https://doi.org/10.1108/JARHE-03-2016-0020

UNESCO (2007). Recognition of Experiential Learning: Prospects for Development in African Countries. (Paper presented at the French National Commission for UNESCO Conference). Paris: UNESCO.

Wihak (2006). State of the Field Review. Prior Learning Assessment and Recognition (PLAR) University of Calgany: A Study Report Submitted to the Canadian Council of Learning, Learning (CCL). 